\title{
Maternal TSH levels at first trimester and subsequent spontaneous miscarriage: a nested case-control study
}

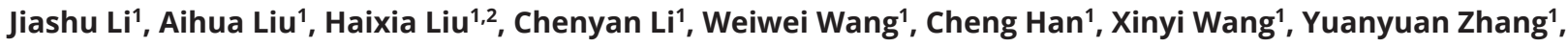 \\ Weiping Teng ${ }^{1}$ and Zhongyan Shan ${ }^{1}$ \\ ${ }^{1}$ Department of Endocrinology and Metabolism, Institute of Endocrinology, Liaoning Provincial Key Laboratory of Endocrine Diseases, The First Affiliated \\ Hospital of China Medical University, China Medical University, Shenyang, Liaoning, China \\ ${ }^{2}$ Department of Endocrinology and Metabolism, The Second Hospital of Dalian Medical University, Dalian, Liaoning, China
}

Correspondence should be addressed to W Teng or Z Shan: twp@vip.163.com or shanzhongyan@medmail.com.cn

\section{Abstract}

Thyroid dysfunction is a frequently found endocrine disorder among reproductively Key Words aged women. Subclinical hypothyroidism is the most common condition of thyroid - thyroid disorders during pregnancy and is defined as manifesting a thyroid-stimulating hormone concentration exceeding the trimester-specific reference value, with a normal free

- reproduction thyroxine concentration. Here, we evaluated the prospective association between spontaneous miscarriage and first-trimester thyroid function. We conducted a case-control study (421 cases and 1684 controls) that was nested. Thyroid-stimulating hormone (TSH), free thyroxine $\left(\mathrm{FT}_{4}\right)$, thyroid-peroxidase antibody (TPOAb) and thyroglobulin antibody (TgAb) status were measured. We found that higher TSH was related to spontaneous miscarriage (OR 1.21; 95\% Cl, 1.13-1.30, $P<0.001)$. Compared with women with TSH levels of $0.4-<2.5 \mathrm{mIU} / \mathrm{L}$, the risk of miscarriage was increased in women with TSH levels of 2.5-<4.87 mIU/L (OR 1.47; 95\% Cl, 1.16-1.87) and TSH greater than $4.87 \mathrm{mIU} / \mathrm{L}$ (OR 1.97; $95 \% \mathrm{Cl}, 1.22-3.18)$. After controlling for the confounding factor, TPOAb positivity status and $\mathrm{FT}_{4}$, the results were similar. The present study showed that higher TSH was associated with miscarriage in early pregnancy. In fact, TSH levels between 2.5 and $4.87 \mathrm{mIU} / \mathrm{L}$ increased the risk for miscarriage, with TSH greater than $4.87 \mathrm{mIU} / \mathrm{L}$ increasing the risk even further.

\section{Introduction}

Thyroid dysfunction is a common endocrine disorder among reproductively aged women (1), with a morbidity of $2-3 \%$. Subclinical hypothyroidism ( $\mathrm{SCH}$ ) is the most common condition of thyroid disorders during pregnancy (2) and is defined as manifesting a thyroid-stimulating hormone (TSH) concentration exceeding the trimesterspecific reference value, with a normal free thyroxine $\left(\mathrm{FT}_{4}\right)$ concentration. However, because of the lack of specific clinical symptoms, $\mathrm{SCH}$ is often ignored.

The fetus does not produce its own thyroid hormone until weeks $10-12$ of gestation; before that, the fetus is dependent upon maternal $\mathrm{T}_{4}$ that crosses the placenta. Due to the lack of thyroid hormone availability, $\mathrm{SCH}$ may be associated with adverse maternal outcomes and perinatal complications $(3,4,5)$ and impaired neurodevelopment in the offspring (6). A meta-analysis showed that $\mathrm{SCH}$ in early pregnancy, compared with normal thyroid function was associated with the occurrence of preeclampsia and an increased risk of perinatal mortality, but not with miscarriage (7). However, recent studies have reported that $\mathrm{SCH}$ during pregnancy was associated with miscarriage $(8,9,10,11)$, and higher maternal TSH levels
This work is licensed under a Creative Commons Attribution-NonCommercial 4.0 International License. ded from Bioscientifica.com at 04/26/2023 12:59:04PM 
have been detected in women who miscarried compared to unaffected women $(12,13,14,15,16)$. Therefore, it still remains controversial as to whether SCH is associated with the risk of miscarriage.

In China, spontaneous miscarriage is increasingly observed in pregnant Chinese women. We conducted a matched nested case-control study based on the Subclinical Hypothyroid in Early Pregnancy Study which was described previously (17), in order to examine the occurrence of miscarriage in relationship to TSH levels in early pregnancy. In the 2011 American Thyroid Association (ATA) guidelines, reference range for TSH during pregnancy was $0.1-2.5 \mathrm{mIU} / \mathrm{L}$ in the first trimester (2). However, according to suggestion of National Academy of Clinical Biochemistry we established the gestation-specific TSH reference range by selecting healthy TPOAb-negative pregnant women with optimal iodine intake and without thyroid illness. We found that upper reference limit for serum TSH concentration in our laboratory in the first trimester was $4.87 \mathrm{mIU} / \mathrm{L}$ (17), based on the evidence stated in the ATA guidelines (2017) (18). We analyzed the association of miscarriage with different TSH levels in the present nested case-control study.

\section{Subjects and methods}

\section{Subjects}

The present investigation was nested within a large-scale population-based study that was begun in three cities in Liaoning Province in China. Unselected pregnant women who attended the Gynecology and Obstetrics clinics in 13 hospitals for their first obstetric visit were recruited between May 2011 and March 2013. These areas were iodine sufficient.

Recruitment criteria included residing in the city for more than 10 years, being between 19 and 40 years old, and having a singleton pregnancy at 4-9 weeks of gestation. Gestational age was determined by last menstruation period and ultrasound of fetus. Exclusion criteria applied to multiple pregnancies, patients with thyroid disease history, diabetes, abnormal liver enzymes and any other chronic diseases, and patients on oral contraceptive regimens or any medical regimens that may affect thyroid function, such as glucocorticoids, dopamine, antiepileptic drugs, anticoagulant therapy, treatment with tricyclics or selective serotonin reuptake inhibitors (SSRIs). All subjects were asked to complete a questionnaire, and their BMI, blood pressure, $\mathrm{FT}_{4}, \mathrm{TSH}$, thyroglobulin antibody (TgAb) and thyroid-peroxidase antibody (TPOAb) were measured.
On this basis, 6516 intrauterine pregnancy women during 4-9 weeks of gestation with a singleton pregnancy were selected as the cohort. We lost contact with 387 of the women. We then carried out a nested case-control study within the remaining cohort. Miscarriage was defined as spontaneous pregnancy loss occurring before 20-week gestation (19). Miscarriage was recorded after ultrasonographic confirmation or histologic evidence of curettage. The control group patients were 1:4 paired with residence, gestation weeks, age ( \pm 1 year) and BMI, by individual. Of these 6129 pregnant women, 442 pregnancies ended in spontaneous miscarriage, and 21 cases failed to match. Thus, 421 women were selected as the case group and 1684 as the control group. Forty and seventy-seven women had a history of smoking and of alcohol consumption, they all quit the habit during pregnancy.

\section{Methods}

All subjects signed consent forms to participate in the study. All participants were followed with an ultrasound examination and thyroid function tests at the endocrine clinics each month. Samples of urine and blood were obtained from each participant in the morning after an overnight fast. All specimens were frozen at $-20^{\circ} \mathrm{C}$ until shipment and assayed as soon as possible.

Serum $\mathrm{FT}_{4}, \mathrm{TSH}, \mathrm{TPOAb}$ and $\mathrm{TgAb}$ were measured in all participants using the electrochemiluminescence immunoassay with Cobas Elesys 601 (Roche Diagnostics). The intra-assay coefficients of variation for serum $\mathrm{FT}_{4}$, $\mathrm{TSH}, \mathrm{TPOAb}$ and $\mathrm{TgAb}$ were $1.57-4.12 \%, 2.24-6.33 \%$, $2.42-5.63 \%$ and $1.3-4.9 \%$, respectively. The interassay coefficients of variation were $1.26-5.76 \%, 4.53-8.23 \%$, $5.23-8.16 \%$ and $2.1-6.9 \%$, respectively. The laboratory reference ranges of TPOAb were $0-34 \mathrm{IU} / \mathrm{mL}$, and $\mathrm{TgAb}$ were $0-115 \mathrm{IU} / \mathrm{mL}$.

Because TSH is not normally distributed in our data, we used SPSS software to convert TSH into a normal distribution. According to the normal score of TSH using Blom's formula, we excluded the values of TSH $\geq 15.29 \mathrm{mIU} / \mathrm{L}$ or $\mathrm{TSH} \leq 0.005 \mathrm{mIU} / \mathrm{L}$. The subjects were divided into four categories according to TSH levels: (1) less than $0.4 \mathrm{mIU} / \mathrm{L}$, (2) $0.4-<2.5 \mathrm{mIU} / \mathrm{L}$, (3) $2.5-<4.87 \mathrm{mIU} / \mathrm{L}$ and (4) greater than $4.87 \mathrm{mIU} / \mathrm{L}$.

\section{Statistical analyses}

The data are presented as mean \pm standard deviation (s.D.) if they show a normal distribution; otherwise, the median and interquartile range (IQR) were used.

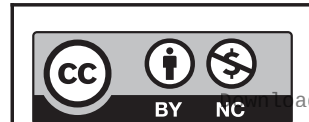


Table 1 Characteristics of the case and control groups.

\begin{tabular}{l}
\hline \\
\hline Age (years) \\
Gestation age (weeks) \\
BMI (kg/m²) \\
Smoking (\%) \\
Alcohol consumption (\%) \\
History of miscarriage (\%) \\
Family history of thyroid disease (\%) \\
High blood pressure (\%) \\
TSH (mIU/L) \\
FT ${ }_{4}$ (pmol/L) \\
TPOAb positivity (\%) \\
TgAb positivity (\%)
\end{tabular}

\begin{tabular}{c} 
Case group $(n=421)$ \\
\hline $29(22-39)$ \\
$7(4-8)$ \\
$21.45(15.63-29.45)$ \\
$9(2.1)$ \\
$17(4.0)$ \\
$42(10.0)$ \\
$17(4.0)$ \\
$13(3.1)$ \\
$2.21(0.25-6.65)$ \\
$15.88(12.28-21.96)$ \\
$47(11.2)$ \\
$58(13.8)$
\end{tabular}

\begin{tabular}{c}
\hline Control group $(n=1684)$ \\
\hline $29(22.13-38)$ \\
$7(4-8)$ \\
$21.34(16.58-28.93)$ \\
$31(1.8)$ \\
$60(3.6)$ \\
$172(10.2)$ \\
$74(4.4)$ \\
$45(2.7)$ \\
$1.77(0.15-5.66)$ \\
$16.04(12.44-21.99)$ \\
$156(9.3)$ \\
$236(14.0)$
\end{tabular}

\begin{tabular}{c}
$\boldsymbol{P}$ value \\
\hline 0.946 \\
1.000 \\
0.782 \\
0.690 \\
0.642 \\
0.885 \\
0.748 \\
0.641 \\
0.000 \\
0.146 \\
0.237 \\
0.900
\end{tabular}

$\mathrm{BMI}$, body mass index; $\mathrm{FT}_{4}$, free thyroxine; TgAb, thyroglobulin antibody; TPOAb, thyroid-peroxidase antibody; TSH, thyroid-stimulating hormone.

All statistical analyses were performed with SPSS, version 20.0 software (IBM). Comparison between case and control groups was by chi-square test for categorical variables and by non-parametric test for continuous variables. Logistic regression analysis was used for univariate analysis. A $P$ value of $<0.05$ was considered to be significant. The Mantel-Haenszel method was used for stratified analysis. Results were presented as odds ratio (OR) and 95\% confidence intervals (95\% CI).

\section{Ethics committee approval}

The experimental procedure described here was approved by the Ethics Committee of China Medical University and was conducted in accordance with approved guidelines and regulations. Informed consent was obtained from every patient.

\section{Results}

\section{Maternal demographic characteristics and thyroid function}

Maternal demographic characteristics of the case and control groups are shown in Table 1. No significant differences were observed between the two groups in the following parameters: median maternal age, gestational age, BMI, smoking history, alcohol consumption, history of miscarriage and family history of thyroid disease, high blood pressure. Serum TSH levels were significantly higher in the case group compared to the control group (2.21 mIU/L IQR $0.25-6.65$ vs $1.77 \mathrm{mIU} / \mathrm{L}$ IQR 0.15-5.66, respectively; $P<0.001$ ). In TPOAb-negative women, serum TSH levels were significantly higher in the case group compared to the control group
(2.39 mIU/L IQR 0.27-5.80 vs 2.02 mIU/L IQR 0.19-4.93, respectively; $P<0.001)$. After additional exclusion of TgAb-positive women, TSH levels were also higher in the case group compared to the control group (2.36 mIU/L IQR 0.33-5.69 vs $1.94 \mathrm{mIU} / \mathrm{L}$ IQR $0.21-4.78$, respectively; $P<0.001)$. No significant differences in $\mathrm{FT}_{4}$ levels, TPOAb and TgAb were observed between the two groups (Table 1).

\section{Gestational age when the miscarriages occurred}

Among the 421 women with a miscarriage, the median gestational age at miscarriage was 10 weeks, IQR 8-12 weeks. In the group with TSH levels $<0.1 \mathrm{mUI} / \mathrm{L}$, a spontaneous miscarriage occurred later than in the other three groups (TSH levels $<0.1 \mathrm{mIU} / \mathrm{L}$ vs $0.1-<2.50 \mathrm{mIU} / \mathrm{L}$ vs $2.50-<4.87 \mathrm{mIU} / \mathrm{L}$ vs greater than $4.87 \mathrm{mIU} / \mathrm{L}: 14$ weeks

Table 2 Logistic regression.

\begin{tabular}{l}
\hline \\
\hline Age (years) \\
Gestation age (weeks) \\
BMI (kg/m²) \\
Smoking (\%) \\
Alcohol consumption (\%) \\
History of miscarriage (\%) \\
Family history of thyroid \\
disease (\%) \\
High blood pressure (\%) \\
TSH (mIU/L) \\
FT (pmol/L) \\
TPOAb positivity (\%) \\
TgAb positivity (\%) \\
\hline
\end{tabular}

\begin{tabular}{c}
\hline $\mathbf{O R}$ \\
\hline 1.01 \\
1.00 \\
1.00 \\
1.16 \\
1.16 \\
0.96 \\
0.86 \\
\\
1.02 \\
1.21 \\
1.00 \\
1.25 \\
1.00 \\
\hline
\end{tabular}

\begin{tabular}{|c|c|}
\hline $95 \% \mathrm{Cl}$ & $P$ value \\
\hline $0.98-1.04$ & 0.723 \\
\hline $0.90-1.10$ & 0.937 \\
\hline $0.97-1.04$ & 0.817 \\
\hline $0.55-2.46$ & 0.692 \\
\hline $0.67-2.01$ & 0.602 \\
\hline $0.67-1.37$ & 0.822 \\
\hline $0.50-1.49$ & 0.587 \\
\hline $0.52-2.00$ & 0.948 \\
\hline $1.13-1.30$ & $<0.001$ \\
\hline 0.97-1.04 & 0.86 \\
\hline $0.88-1.78$ & 0.215 \\
\hline $0.73-1.37$ & 0.993 \\
\hline
\end{tabular}

95\% Cl, 95\% confidence intervals; $\mathrm{BMI}$, body mass index; $\mathrm{FT}_{4}$, free thyroxine; OR, odds ratio; TgAb, thyroglobulin antibody; TPOAb, thyroid-peroxidase antibody; TSH, thyroid-stimulating hormone. 
Table 3 Odds of miscarriage by serum TSH levels in the first trimester.

\begin{tabular}{|c|c|c|c|c|c|c|c|c|c|c|}
\hline \multirow{2}{*}{$\begin{array}{l}\text { TSH } \\
(\mathrm{mlU} / \mathrm{L})\end{array}$} & \multirow{2}{*}{$\begin{array}{c}\text { Case } \\
(n=418)(\%)\end{array}$} & \multirow{2}{*}{$\begin{array}{c}\text { Control } \\
(n=1670)(\%)\end{array}$} & \multicolumn{2}{|c|}{ Unadjusted } & \multicolumn{2}{|c|}{$\begin{array}{c}\text { Adjusted for } \\
\text { confounding factors }^{a}\end{array}$} & \multicolumn{2}{|c|}{$\begin{array}{c}\text { Adjusted for } \\
\text { confounding factors }^{b}\end{array}$} & \multicolumn{2}{|c|}{ Adjusted for $\mathrm{FT}_{4}$} \\
\hline & & & $P$ value & OR $(95 \% \mathrm{Cl})$ & $P$ value & OR $(95 \% \mathrm{Cl})$ & $P$ value & OR $(95 \% \mathrm{Cl})$ & $P$ value & OR $(95 \% \mathrm{CI})^{c}$ \\
\hline$<0.4$ & $12(11.5)$ & $92(88.5)$ & 0.096 & $0.59(0.32-1.10)$ & 0.095 & $0.59(0.32-1.10)$ & 0.053 & $0.53(0.28-1.01)$ & 0.053 & $0.53(0.28-1.01)$ \\
\hline $0.4-<2.5$ & $239(18.1)$ & 1084 (81.9) & & 1 & & 1 & & 1 & & 1 \\
\hline $2.5-<4.87$ & $141(24.5)$ & $434(75.5)$ & 0.001 & $1.47(1.16-1.87)$ & 0.001 & $1.48(1.17-1.88)$ & 0.001 & $1.51(1.19-1.91)$ & 0.001 & $1.50(1.18-1.90)$ \\
\hline$\geq 4.87$ & $26(30.2)$ & $60(69.8)$ & 0.006 & $1.97(1.22-3.18)$ & 0.005 & $1.99(1.23-3.22)$ & 0.004 & $2.05(1.26-3.32)$ & 0.004 & $2.02(1.25-3.28)$ \\
\hline
\end{tabular}

IQR 9-19 vs 10 weeks IQR 8-12 vs 9 weeks IQR 8-11 vs 9 weeks IQR 8-12, respectively).

\section{Logistic regression analysis}

The results of the logistic regression analysis are displayed in Table 2. TSH level was a risk factor for spontaneous miscarriage (OR, 1.21; 95\% CI, 1.13-1.30, $P<0.001)$. However, the association of $\mathrm{FT}_{4}$ (OR, 1.00; 95\% CI, 0.97-1.04, $P=0.86$ ), TPOAb (OR, 1.25; 95\% CI, 0.88-1.78, $P=0.215)$ and TgAb (OR, 1.00; 95\% CI, $0.73-1.37, P=0.993)$ with miscarriage was not significant in the analysis.

\section{Miscarriage outcomes by first-trimester TSH}

Compared with TSH levels between 0.4 and $2.5 \mathrm{mIU} / \mathrm{L}$, a clear increase in the odds of miscarriage was observed with TSH levels between 2.5 and $4.87 \mathrm{mIU} / \mathrm{L}$ (OR 1.47; 95\% CI, 1.16-1.87, $P=0.001$ ), with the greater impact observed with TSH levels greater than $4.87 \mathrm{mIU} / \mathrm{L}$ (OR, 1.97; 95\% CI, 1.22-3.18, $P=0.006$ ) (Table 3). Individuals with TSH less than $0.4 \mathrm{mIU} / \mathrm{L}$ had an OR with respect to miscarriage of less than 1 , but this was not statistically significant. After controlling for the confounding factor age, alcohol consumption, smoking status, BMI, history of miscarriage and high blood pressure, the results were similar (OR 1.48; 95\% CI, 1.17-1.88, $P=0.001$, OR 1.99; 95\% CI, 1.23-3.22, $P=0.005$, respectively). After controlling for $\mathrm{FT}_{4}$ and in TPOAb-negative women only, the risks of miscarriage

Table 4 Odds of miscarriage by serum TSH levels in the first trimester in TPOAb-negative women only.

\begin{tabular}{|c|c|c|c|c|}
\hline $\begin{array}{l}\text { TSH } \\
(\mathrm{mlU} / \mathrm{L})\end{array}$ & $\begin{array}{c}\text { Case } \\
(n=373)(\%)\end{array}$ & $\begin{array}{c}\text { Control } \\
(n=1525)(\%)\end{array}$ & P value & OR $(95 \% \mathrm{Cl})$ \\
\hline$<0.4$ & $12(12.6)$ & $83(87.4)$ & 0.207 & $0.67(0.36-1.25)$ \\
\hline $0.4-<2.5$ & $221(17.8)$ & 1024 (82.2) & & 1 \\
\hline $2.5-<4.87$ & $121(24.1)$ & 381 (75.9) & 0.003 & $1.47(1.15-1.89)$ \\
\hline$\geq 4.87$ & $19(35.2)$ & 35 (64.8) & 0.002 & $2.52(1.41-4.48)$ \\
\hline
\end{tabular}

were increased (Tables 3 and 4). Where TSH was stratified by quintiles, results are given in Tables 5 and 6 .

\section{Discussion}

The current study was performed to gain insight into the impact of TSH levels on spontaneous miscarriage. We found that TSH levels between 2.5 and $4.87 \mathrm{mIU} / \mathrm{L}$ were correlated with increased risk of miscarriage ( $\mathrm{OR}=1.47)$. In addition, TSH levels above the upper limit of the gestation-specific reference range $(\geq 4.87 \mathrm{mIU} / \mathrm{L})$ increased the risk even further $(\mathrm{OR}=1.97)$. This is an important finding to discuss, because according to the upper limit of TSH (which was $2.5 \mathrm{mIU} / \mathrm{L}$ ), 27.8\% pregnancies would be diagnosed with SCH in our study $(8,17)$. Whether these women suffered from other adverse obstetric outcomes, such as fetal growth restriction and postpartum hemorrhage, requires further analysis.

Although the correlations between TSH levels and spontaneous miscarriage have been reported worldwide, the conclusions are controversial $(8,9,12$, $13,14,20,21)$. Inter-study differences may be caused by study design, sample size or varying demographics. The majority of these studies were derived using a gestational age of 7-12 weeks; however, spontaneous miscarriage could occur before 7 weeks. Given the previous one-child-per-family policy in China, many pregnant women visit clinics before 8 weeks of gestation for prenatal care, some even before 6 weeks. Therefore, we chose pregnant women whose first visit was between 4 and 9 gestational weeks, and thus, we were able to evaluate whether high early-pregnancy TSH levels would increase the risks for spontaneous miscarriage. Early levothyroxine treatment, then, may reduce the risk of miscarriage (16).

This study was a nested case-control study, and data were obtained before the occurrence of disease, so there had less recall bias. Members in the cohort had the same

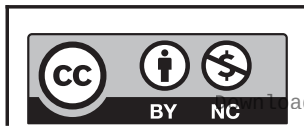

This work is licensed under a Creative Commons Attribution-NonCommercial 4.0 International License. ded from Bioscientifica.com at 04/26/2023 12:59:04PM via free access 
Table 5 Odds of miscarriage by serum TSH levels in the first trimester stratified by quintiles.

\begin{tabular}{|c|c|c|}
\hline $\begin{array}{l}\text { TSH } \\
(\mathrm{mlU} / \mathrm{L})\end{array}$ & $\begin{array}{c}\text { Case } \\
(n=418)(\%)\end{array}$ & $\begin{array}{c}\text { Control } \\
(n=1670)(\%)\end{array}$ \\
\hline$<1.04$ & 52 (12.7) & 357 (87.3) \\
\hline $1.04-<1.60$ & $61(14.4)$ & 363 (85.6) \\
\hline $1.60-<2.17$ & $86(20.7)$ & 329 (79.3) \\
\hline $2.17-<3.04$ & 108 (25.7) & 312 (74.3) \\
\hline$\geq 3.04$ & $111(26.4)$ & 309 (73.6) \\
\hline
\end{tabular}

\begin{tabular}{cc}
$\frac{\text { Unadjusted }}{P \text { value }}$ & $\frac{\mathrm{OR}(95 \% \mathrm{Cl})}{0.481}$ \\
$0.87(0.58-1.29)$ \\
1 \\
0.016 & $1.56(1.09-2.23)$ \\
$<0.001$ & $2.06(1.45-2.92)$ \\
$<0.001$ & $2.14(1.51,3.03)$ \\
\hline
\end{tabular}

\begin{tabular}{l} 
Adjus \\
confoundi \\
\hline$\frac{P \text { value }}{0.477}$ \\
0.015 \\
$<0.001$ \\
$<0.001$
\end{tabular}

Adjusted for unding factors ${ }^{a}$

a Confounding factors include age, alcohol consumption, smoking status, BMI, history of miscarriage and high blood pressure. ${ }^{\mathrm{b} C o n f o u n d i n g ~ f a c t o r s ~}$ include $\mathrm{FT}_{4}$, age, alcohol consumption, smoking status, BMI, history of miscarriage and high blood pressure. 'The OR expresses the risk of miscarriage after controlling $\mathrm{FT}_{4}$.

exposure time, so the statistical and test effectiveness were higher than those in the traditional case-control study.

Furthermore, we matched the control and case groups with residence, number of gestational weeks, age and BMI in order to increase the effectiveness of the study. After controlling for these factors, the effects of TSH levels on spontaneous miscarriage were obvious. We also took into consideration alcohol consumption, smoking status, history of miscarriage and TPOAb positivity status, as TPOAb-positive pregnant women are generally considered to have a higher risk for premature delivery and miscarriage $(22,23,24,25)$, and elevated serum TPOAb levels are associated with higher TSH and lower $\mathrm{T}_{4}$ values (26).

An increasing number of studies suggest that $\mathrm{SCH}$ is associated with spontaneous abortion. However, the underlying mechanism is not clear. Despite the normal serum $\mathrm{FT}_{4}$ in $\mathrm{SCH}$ patients, thyroid hormone shortage in the tissues may be the cause of miscarriage. TSH can increase the expression of LIF and its receptor LIFR in endometrial stromal cells, stimulation expression of glucose transporter (GLUT1) in the Ishikawa cell line, which is further involved in endometrial glucose transport (27). Other studies have found the mirrorimage symmetry relation between thyrotropin (TSH) and human chorionic gonadotropin levels. A decrease in HCG concentration can lead to miscarriage.

Table 6 Odds of miscarriage by serum TSH levels in the first trimester stratified by quintiles in TPOAb-negative women only.

\begin{tabular}{|c|c|c|c|c|}
\hline TSH (mIU/L) & $\begin{array}{c}\text { Case } \\
(n=373)(\%)\end{array}$ & $\begin{array}{c}\text { Control } \\
(n=1523)(\%)\end{array}$ & $P$ value & OR $(95 \% \mathrm{Cl})$ \\
\hline$<1.04$ & 47 (12.3) & 336 (87.7) & 0.429 & $0.85(0.56-1.28)$ \\
\hline $1.04-<1.60$ & $58(14.2)$ & $351(85.8)$ & & 1 \\
\hline $1.60-<2.17$ & $78(20.6)$ & 300 (79.4) & 0.017 & $1.57(1.08-2.29)$ \\
\hline $2.17-<3.04$ & 103 (26.5) & 286 (73.5) & $<0.001$ & $2.18(1.52-3.12)$ \\
\hline$\geq 3.04$ & $87(25.8)$ & $250(74.2)$ & $<0.001$ & $2.11(1.46-3.05)$ \\
\hline $\begin{array}{l}\text { https://ec.bic } \\
\text { https://doi.o }\end{array}$ & $\begin{array}{l}\text { entifica.com } \\
0.1530 / E C-19\end{array}$ & & Publis & $\begin{array}{l}\text { (c) } 2019 \text { The authors } \\
\text { hed by Bioscientifica Ltd }\end{array}$ \\
\hline
\end{tabular}

However, this study has several limitations. First, it lacks data on some potential confounding factors such as environmental toxins, irregular menstruation, family history of miscarriage and anti-phospholipid antibodies. Second, chromosomal anomalies and HCG values were not evaluated. Third, matched case-control study wastes some data and reduces the amount of statistical information. Fourth, this study may lead to measurement bias or omission.

In conclusion, we found that pregnant women with elevated TSH levels had an increased risk of miscarriage in early pregnancy. In fact, TSH levels between 2.5 and $4.87 \mathrm{mIU} / \mathrm{L}$ increased the risk for miscarriage, with $\mathrm{TSH}$ greater than $4.87 \mathrm{mIU} / \mathrm{L}$ increasing the risk even further.

\section{Declaration of interest}

The authors declare that there is no conflict of interest that could be perceived as prejudicing the impartiality of the research reported.

\section{Funding}

This work was supported by the National Science and Technology Support Program (2014BAI06B02); Chinese National Natural Science Foundation (81570709, U1508219); Health and Medicine Research Foundation in Shenyang City (17-230-9-02).

\section{Acknowledgments}

The authors gratefully acknowledge the invaluable contributions of doctors from the Gynecology and Obstetrics clinics in the 13 hospitals in Liaoning Province and are indebted to the residents who participated in this study.

\section{References}

1 Rashid M \& Rashid MH. Obstetric management of thyroid disease. Obstetrical and Gynecological Survey 200762 680-688; quiz 691. (https://doi.org/10.1097/01.ogx.0000281558.59184.b5)

2 Stagnaro-Green A, Abalovich M, Alexander E, Azizi F, Mestman J, Negro R, Nixon A, Pearce EN, Soldin OP, Sullivan S, et al. Guidelines of the American Thyroid Association for the diagnosis and management of thyroid disease during pregnancy and postpartum. Thyroid 201121 1081-1125. (https://doi.org/10.1089/ thy.2011.0087)

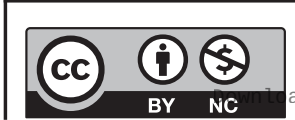

This work is licensed under a Creative Commons Attribution-NonCommercial 4.0 International License. ded from Bioscientifica.com at 04/26/2023 12:59:04PM 
3 Chen LM, Du WJ, Dai J, Zhang Q, Si GX, Yang H, Ye EL, Chen QS, Yu LC, Zhang C, et al. Effects of subclinical hypothyroidism on maternal and perinatal outcomes during pregnancy: a single-center cohort study of a Chinese population. PLoS ONE 20149 e109364. (https://doi.org/10.1371/journal.pone.0109364)

4 Casey BM, Dashe JS, Wells CE, McIntire DD, Byrd W, Leveno KJ \& Cunningham FG. Subclinical hypothyroidism and pregnancy outcomes. Obstetrics and Gynecology 2005105 239-245. (https://doi. org/10.1097/01.AOG.0000152345.99421.22)

5 Wilson KL, Casey BM, McIntire DD, Halvorson LM \& Cunningham FG. Subclinical thyroid disease and the incidence of hypertension in pregnancy. Obstetrics and Gynecology 2012119 315-320. (https://doi.org/10.1097/AOG.0b013e318240de6a)

6 Li Y, Shan Z, Teng W, Yu X, Li Y, Fan C, Teng X, Guo R, Wang H, Li J, et al. Abnormalities of maternal thyroid function during pregnancy affect neuropsychological development of their children at 25-30 months. Clinical Endocrinology 201072 825-829. (https://doi. org/10.1111/j.1365-2265.2009.03743.x)

7 van den Boogaard E, Vissenberg R, Land JA, van Wely M, van der Post JA, Goddijn M \& Bisschop PH. Significance of (sub)clinical thyroid dysfunction and thyroid autoimmunity before conception and in early pregnancy: a systematic review. Human Reproduction Update 201117 605-619. (https://doi.org/10.1093/humupd/ dmr024)

8 Negro R, Schwartz A, Gismondi R, Tinelli A, Mangieri T \& StagnaroGreen A. Increased pregnancy loss rate in thyroid antibody negative women with TSH levels between 2.5 and 5.0 in the first trimester of pregnancy. Journal of Clinical Endocrinology and Metabolism 201095 E44-E48. (https://doi.org/10.1210/jc.2010-0340)

9 Wang S, Teng WP, Li JX, Wang WW \& Shan ZY. Effects of maternal subclinical hypothyroidism on obstetrical outcomes during early pregnancy. Journal of Endocrinological Investigation 201235 322-325. (https://doi.org/10.3275/7772)

10 Liu H, Shan Z, Li C, Mao J, Xie X, Wang W, Fan C, Wang H, Zhang H, Han C, et al. Maternal subclinical hypothyroidism, thyroid autoimmunity, and the risk of miscarriage: a prospective cohort study. Thyroid 201424 1642-1649. (https://doi.org/10.1089/ thy.2014.0029)

11 Khalid AS, Joyce C \& O'Donoghue K. Prevalence of subclinical and undiagnosed overt hypothyroidism in a pregnancy loss clinic. Irish Medical Journal 2013106 107-110.

12 Schneuer FJ, Nassar N, Tasevski V, Morris JM \& Roberts CL. Association and predictive accuracy of high TSH serum levels in first trimester and adverse pregnancy outcomes. Journal of Clinical Endocrinology and Metabolism 201297 3115-3122. (https://doi. org/10.1210/jc.2012-1193)

13 Benhadi N, Wiersinga WM, Reitsma JB, Vrijkotte TG \& Bonsel GJ. Higher maternal TSH levels in pregnancy are associated with increased risk for miscarriage, fetal or neonatal death. European Journal of Endocrinology 2009160 985-991. (https://doi.org/10.1530/ EJE-08-0953)

14 Ashoor G, Maiz N, Rotas M, Jawdat F \& Nicolaides KH. Maternal thyroid function at 11 to 13 weeks of gestation and subsequent fetal death. Thyroid 201020 989-993. (https://doi.org/10.1089/ thy.2010.0058)

15 Dal Lago A, Vaquero E, Pasqualetti P, Lazzarin N, De Carolis C, Perricone R \& Moretti C. Prediction of early pregnancy maternal thyroid impairment in women affected with unexplained recurrent miscarriage. Human Reproduction 201126 1324-1330. (https://doi. org/10.1093/humrep/der069)
16 Taylor PN, Minassian C, Rehman A, Iqbal A, Draman MS, Hamilton W, Dunlop D, Robinson A, Vaidya B, Lazarus JH, et al. TSH levels and risk of miscarriage in women on long-term levothyroxine: a communitybased study. Journal of Clinical Endocrinology and Metabolism 201499 3895-3902. (https://doi.org/10.1210/jc.2014-1954)

17 Li C, Shan Z, Mao J, Wang W, Xie X, Zhou W, Li C, Xu B, Bi L, Meng T, et al. Assessment of thyroid function during first-trimester pregnancy: what is the rational upper limit of serum TSH during the first trimester in Chinese pregnant women? Journal of Clinical Endocrinology and Metabolism 201499 73-79. (https://doi. org/10.1210/jc.2013-1674)

18 Alexander EK, Pearce EN, Brent GA, Brown RS, Chen H, Dosiou C, Grobman WA, Laurberg P, Lazarus JH, Mandel SJ, et al. 2017 Guidelines of the American Thyroid Association for the diagnosis and management of thyroid disease during pregnancy and the postpartum. Thyroid 201727 315-389. (https://doi.org/10.1089/ thy.2016.0457)

19 Keyhan S, Muasher L \& Muasher SJ. Spontaneous abortion and recurrent pregnancy loss: etiology, diagnosis, treatment. In Comprehensive Gynecology E-Book, Chapter 16, pp 329.e2-347. e2. Eds RA Lobo, DM Gerhenson \& GM Lentz. 2016. Amsterdam, Netherlands: Elsevier Health Sciences.

20 Ajmani SN, Aggarwal D, Bhatia P, Sharma M, Sarabhai V \& Paul M. Prevalence of overt and subclinical thyroid dysfunction among pregnant women and its effect on maternal and fetal outcome. Journal of Obstetrics and Gynaecology of India 201464 105-110. (https://doi.org/10.1007/s13224-013-0487-y)

21 Nazarpour S, Ramezani Tehrani F, Simbar M \& Azizi F. Thyroid dysfunction and pregnancy outcomes. Iranian Journal of Reproductive Medicine 201513 387-396.

22 Karakosta P, Alegakis D, Georgiou V, Roumeliotaki T, Fthenou E, Vassilaki M, Boumpas D, Castanas E, Kogevinas M \& Chatzi L. Thyroid dysfunction and autoantibodies in early pregnancy are associated with increased risk of gestational diabetes and adverse birth outcomes. Journal of Clinical Endocrinology and Metabolism 2012 97 4464-4472. (https://doi.org/10.1210/jc.2012-2540)

23 Ghafoor F, Mansoor M, Malik T, Malik MS, Khan AU, Edwards R \& Akhtar W. Role of thyroid peroxidase antibodies in the outcome of pregnancy. Journal of the College of Physicians and Surgeons 200616 468-471. (https://doi.org/7.2006/JCPSP.468471)

24 Glinoer D, Riahi M, Grun JP \& Kinthaert J. Risk of subclinical hypothyroidism in pregnant women with asymptomatic autoimmune thyroid disorders. Journal of Clinical Endocrinology and Metabolism 199479 197-204. (https://doi.org/10.1210/ jcem.79.1.8027226)

25 Negro R, Schwartz A, Gismondi R, Tinelli A, Mangieri T \& StagnaroGreen A. Thyroid antibody positivity in the first trimester of pregnancy is associated with negative pregnancy outcomes. Journal of Clinical Endocrinology and Metabolism 201196 E920-E924. (https:// doi.org/10.1210/jc.2011-0026)

26 Pearce EN, Oken E, Gillman MW, Lee SL, Magnani B, Platek D \& Braverman LE. Association of first-trimester thyroid function test values with thyroperoxidase antibody status, smoking, and multivitamin use. Endocrine Practice 200814 33-39. (https://doi. org/10.4158/EP.14.1.33)

27 Aghajanova L, Stavreus-Evers A, Lindeberg M, Landgren BM, Sparre LS \& Hovatta O. Thyroid-stimulating hormone receptor and thyroid hormone receptors are involved in human endometrial physiology. Fertility and Sterility 201195 230-237, 237.e1-237.e2. (https://doi.org/10.1016/j.fertnstert.2010.06.079)

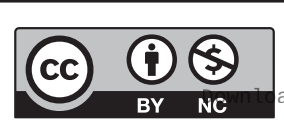

